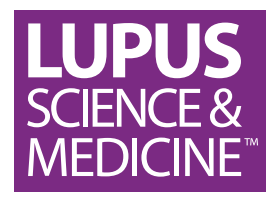

\title{
Dialogue: what can we learn about the relationship between systemic lupus erythematosus and haematological malignancies from linking disease registries?
}

\author{
Rosalind Ramsey-Goldman, ${ }^{1}$ Sasha Bernatsky, ${ }^{2}$ Ann Clarke ${ }^{3}$
}

To cite: Ramsey-Goldman R, Bernatsky S, Clarke A. Dialogue: what can we learn about the relationship between systemic lupus erythematosus and haematological malignancies from linking disease registries?. Lupus Science \& Medicine 2014;1:e000068. doi:10.1136/lupus-2014000068

Received 2 December 2014 Accepted 3 December 2014

\section{Linked}

- http://dx.doi.org/10.1136/ lupus-2014-000051

CrossMark

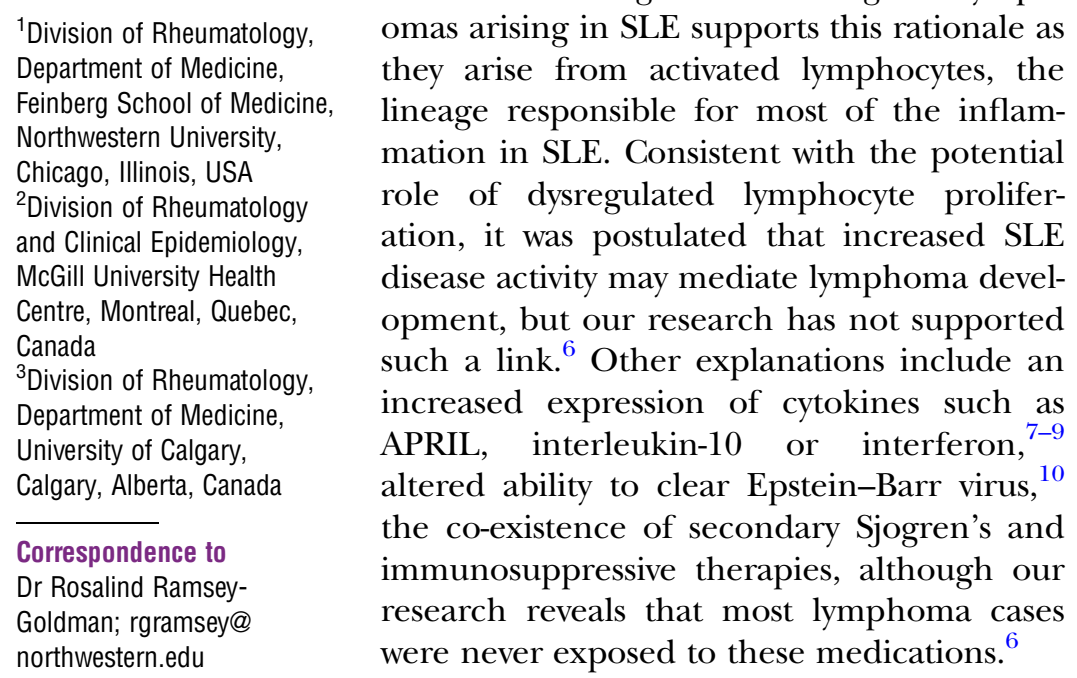

In systemic lupus erythematosus (SLE), there appears to be specific differences in the cancer susceptibility compared with the general population. While the overall cancer incidence rate in patients with SLE is increased about $14 \%,{ }^{1}$ the standardised incidence ratio of a given cancer is largely dependent on the cancer type. Prominent increases are noted in haematological malignancies (HM), ${ }^{23}$ as well as lung, thyroid and vulvar cancer. ${ }^{1}{ }^{4}$ While $\mathrm{HM}$ overall are increased threefold, the risk of non-Hodgkin's lymphoma is increased fourfold, with a predominance of the diffuse large B cell subtype (DLBCL) ${ }^{1}$ nonlymphoma HM, including leukaemia, are increased almost twofold and Hodgkin's lymphoma and multiple myeloma trend towards an approximately twofold increase. ${ }^{1}$ Several hypotheses are advanced to explain this heightened risk, including dysregulated lymphocyte proliferation, which may promote oncogene translocation, favouring lymphoma development; ${ }^{5}$ the predominance of DLBCL among the non-Hodgkin's lymphmas arising in SLE supports this rationale as ineage responsible for most of the inflammation in SLE. Consistent with the potential role of dysregulated lymphocyte proliferation, it was postulated that increased SLE disease activity may mediate lymphoma development, but our research has not supported such a link. ${ }^{6}$ Other explanations include an increased expression of cytokines such as APRIL, interleukin-10 or interferon ${ }^{7-9}$ ugh our were never exposed to these medications.
In contrast to $\mathrm{HM}$, the incidence of certain hormone-sensitive cancers is found to be consistently lower among patients with SLE including a reduced risk of breast, ovarian, endometrial and prostate cancers. ${ }^{1}$ Hormonal changes, genetics, as well as drugs used in SLE such as non-steroidal antiinflammatory drugs among others are postulated as potential reasons for this decreased risk. ${ }^{11}$

This retrospective study examines the relationship between HM and SLE by linking disease registries at one institution. Individuals with both diagnoses were divided into those with SLE first followed by HM at least 1 year later and those with HM before or concurrent with the diagnosis of SLE. ${ }^{12}$ The majority of the patients were in the after SLE group (29/45), and of the 16 in the before or concurrent SLE and HM group, 9/16 had HM more than 2 years prior to SLE and 7 had HM and SLE concurrently. HM after malignancy group confirmed previous findings of the predominant cell type, DLBCL, and their poor prognosis. The new information provided here describes a more favourable prognosis observed in HM before SLE and patients with concurrent HM/SLE who are usually omitted from previous reports that eliminate prior or concurrent malignancy in patients who are diagnosed with SLE. It is perhaps not surprising that those who developed HM prior to the diagnosis of SLE had a more favourable prognosis as they survived their HM and then remained alive long enough to develop SLE. Two patients with SLE who received a renal transplant for end-stage renal disease secondary to SLE developed late HM, which was described as post-transplant lymphoproliferative disorder (PTLD). These patients may be 
very different than those patients with SLE not undergoing transplant, and the relationship and/or mechanism of the relationship between SLE and HM is likely to be different. The authors also raise the possibility that SLE is a paraneoplastic syndrome when HM and SLE are diagnosed concurrently.

The authors have broadened the spectrum of $\mathrm{HM}$ in SLE raising new questions about mechanisms and the impact of treatment in HM before SLE and patients with SLE who later develop PTLD. Assuming HM before patients with SLE were treated for HM that included immunosuppression for early-stage disease and many achieved remission, then why do these patients still develop SLE later including nephritis? What does this tell us about implicating genetic, immunological or environmental factors as contributors to either or both conditions? Are SLE transplant patients who subsequently develop PTLD different from other transplant recipients who do not have SLE but presumably are exposed to similar immunosuppression following renal replacement or does the underlying SLE predispose to PTLD irrespective of treatment?

Although new observations were made in this retrospective study, we still need to make progress in gaining additional insight as to the mechanism behind the coexistence of these two diseases. What is the driver or the important interactions between genetics, medications, immune dysfunction or the environment (eg, infections, hormones)?

Competing interests None.

Provenance and peer review Commissioned; internally peer reviewed.

Data sharing statement No additional data are available.
Open Access This is an Open Access article distributed in accordance with the Creative Commons Attribution Non Commercial (CC BY-NC 4.0) license, which permits others to distribute, remix, adapt, build upon this work noncommercially, and license their derivative works on different terms, provided the original work is properly cited and the use is non-commercial. See: http:// creativecommons.org/licenses/by-nc/4.0/

\section{REFERENCES}

1. Bernatsky S, Ramsey-Goldman R, Labrecque J, et al. Cancer risk in systemic lupus: An updated international multi-centre cohort study. $J$ Autoimmun 2013;42:130-5.

2. Parikh-Patel $A$, White $\mathrm{RH}$, Allen $\mathrm{M}$, et al. Cancer risk in a cohort of patients with systemic lupus erythematosus (SLE) in California. Cancer Causes Control 2008;19:887-94.

3. Mellemkjaer L, Andersen V, Linet MS, et al. Non-Hodgkin's lymphoma and other cancers among a cohort of patients with systemic lupus erythematosus. Arthritis Rheum 1997;40:761-8.

4. Bjornadal L, Lofstrom B, Yin L, et al. Increased cancer incidence in a Swedish cohort of patients with systemic lupus erythematosus. Scand J Rheum 2002;31:66-71.

5. Ott G, Rosenwald A. Molecular pathogenesis of follicular lymphoma Haematologica 2008;93:1773-6.

6. Bernatsky S, Ramsey-Goldman R, Joseph L, et al. Lymphoma risk in systemic lupus: effects of disease activity versus treatment. Ann Rheum Dis 2014;73:138-42.

7. Tarella C, Gueli A, Ruella M, et al. Lymphocyte transformation and autoimmune disorders. Autoimmun Rev 2013;12:802-13.

8. Cortes J, Kurzrock R. Interleukin-10 in non-hodgkin's lymphoma. Leuk Lymphoma 1997;26:251-9.

9. Choubey D, Deka R, Ho SM. Interferon-inducible ifi16 protein in human cancers and autoimmune diseases. Front Biosci 2008;13:598-608.

10. Draborg AH, Duuk K, Houen G. Epstein-Barr virus in systemic autoimmune diseases. Clin Dev Immunol 2013;2013:535738.

11. Bernatsky S, Ramsey-Goldman R, Foulkes WD, et al. Breast, ovarian, and endometrial malignanices in systemic lupus erythematosus: a meta-analysis. Br J Cancer 2011;104:1478-81.

12. Knight JS, Blayney DW, Somers ED. Patients with systemic lupus erythematosus and haematological malignancy at a tertiary care centre: timing, histopathology and therapy. Lupus Sci Med 2014;1: e000051. 